\title{
Toward a TQM Paradigm: Using SERVQUAL to Measure Library Service Quality
}

\section{Vicki Coleman, Yi (Daniel) Xiao, Linda Bair, and Bill Chollett}

\begin{abstract}
This study provides the results of a survey conducted in the fall of 1994 by the Sterling C. Evans Library to measure service quality. This general user survey provided feedback from customers on their minimum, perceived, and desired levels of service from an academic library. The devised measuring instrument is based on SERVQUAL, a service quality survey created by Leonard L. Berry, A. Parasuraman, and Valarie A. Zeithaml. The SERVQUAL survey is designed to measure service quality in five dimensions: tangibles, reliability, responsiveness, assurance, and empathy. Survey results showed a discrepancy in the quality of the services provided by the library and those desired by its customers.
\end{abstract}

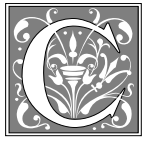

oncepts of total quality management (TQM) indicate that evaluation of library service quality is based on customer perception. ${ }^{1}$ This raises the question: How do you measure service quality in terms of a provider's performance with respect to a customer's expectations? For this study, SERVQUAL provided the solution. Developed in 1988 by Leonard L. Berry, A. Parasuraman, and Valarie A. Zeithaml, SERVQUAL is an instrument designed to measure service quality on the basis of a customer's minimum, perceived, and desired levels of performance.

This study examines the results of the SERVQUAL survey distributed at a large university. The objectives of the survey were: (1) to define library service quality, (2) to determine how to improve it, and (3) to assess the dimensions of quality most important to library customers. For this study, service quality is determined as the discrepancy between the minimum, perceived, and desired levels of performance across five dimensions (tangibles, reliability, responsiveness, assurance, and empathy). Exceeding what customers expect from the service is the key to delivering high-quality service. ${ }^{2}$ TQM principles emphasize the use of a decentralized, team-oriented approach to address the issues causing the gaps in customer expectations and perceptions. ${ }^{3}$ Analy-

All four authors work at the Sterling C. Evans Library at Texas AEM University. Vicki Coleman is Head of Electronic Reference Services; e-mail:vcoleman@tamu.edu. Yi (Daniel) Xiao is Assistant Head of Electronic Reference Services; e-mail: danxiao@tamu.edu. Linda Bair is Senior Library Specialist and Chairperson of the Library Service Quality Committee; e-mail: l-bair@tamu.edu. Bill Chollett is System Administrator e-mail:b-chollett@tamu.edu. 
sis of the survey results offers managers and quality teams a guide for devising strategic plans to improve service quality in the library.

\section{Literature Review}

A review of the literature on service

\section{Understanding customer expectations is a prerequisite for delivering superior service.}

quality in libraries was conducted before and after this study. The literature review prior to the study revealed only one documented source of a library actually using the SERVQUAL instrument. Françoise Hebert uses SERVQUAL specifically for the investigation of interlibrary loan service quality in large public libraries in Canada. In her data analysis, she compares the library's measures of interlibrary loan service quality to those of the responding customers. Her study concludes with the finding that there is a mismatch between library measures of interlibrary loan performance, based on fill rate and turnaround time, and customer measures of quality, based on disconfirmation theory. ${ }^{4}$

Where Hebert focuses on one library service (interlibrary loan), the purpose of this study was to obtain from library customers an "aura" of overall library service. First, it was necessary to understand the nature and determinants of customer expectations; understanding customer expectations is a prerequisite for delivering superior service. Berry, Parasuraman, and Zeithaml suggest that there are three levels of customer expec- tations: desired service (which reflects what customers want); adequate service (the standard customers are willing to accept); and predicted service (the level of service customers believe is likely to occur). ${ }^{5}$ Their research also supports the theory that customers generally use five factors, or dimensions, as their criteria for judging service quality. The dimensions as listed in table 1 are not mutually exclusive but provide a foundation for understanding what customers expect from service providers. ${ }^{6}$

Upon completion of this study, another literature search was conducted. The authors found that Marilyn D. White and Eileen G. Abels had conducted a survey of the service marketing literature for models and data-gathering instruments measuring service quality. ${ }^{8}$ That study focuses on SERVQUAL and SERVPERF (an instrument used to generate a performance-based measure of service quality), and assesses their applicability to special libraries and information centers. The authors' findings show that the validity of the individual twenty-two items on the SERVQUAL survey has rarely been disputed. However, there has been criticism of SERVQUAL in other areas, specifically, the SERVQUAL scale's theoretical base

\begin{tabular}{|c|c|}
\hline \multicolumn{2}{|c|}{$\begin{array}{c}\text { TABLE } 1 \\
\text { Five Dimensions of Quality } \text { Defined }^{7}\end{array}$} \\
\hline Dimensions & Definitions \\
\hline Reliability & $\begin{array}{l}\text { The ability to perform the promised } \\
\text { service dependably and accurately. }\end{array}$ \\
\hline Responsiveness & $\begin{array}{l}\text { The willingness to help customers and } \\
\text { provide prompt service. }\end{array}$ \\
\hline Assurance & $\begin{array}{l}\text { The knowledge and courtesy of } \\
\text { employees and their ability to convey } \\
\text { trust and confidence. }\end{array}$ \\
\hline Empathy & $\begin{array}{l}\text { The caring, individualized attention } \\
\text { given to customers. }\end{array}$ \\
\hline Tangibles & $\begin{array}{l}\text { The appearance of physical facilities, } \\
\text { equipment, personnel, and communi- } \\
\text { cation materials. }\end{array}$ \\
\hline
\end{tabular}




\section{FIGURE 1 \\ Evans Library Customer Satisfaction Survey (Part 1)}

We would like your impressions about Evans' service performance relative to your expectations. Please think about the two different levels of expectations as defined below:

\section{Minimum Service Level: the minimum service performance you consider adequate \\ Desired Service Level: the level of service performance you desire}

For each of the following statements, please indicate: (a) your minimum service level by circling one of the numbers in the first column; (b) your desired service level by circling one of the numbers in the second column; and (c) your perception of Evans' service by circling one of the numbers in the third column.

Q.2 Employees who are consistently courteous

Q.3 Employees who deal with customers in a caring fashion

\begin{tabular}{|c|c|c|c|}
\hline When it comes to... & $\begin{array}{l}\text { My Minimum Service } \\
\text { Level Is: }\end{array}$ & $\begin{array}{l}\text { My Desired Service } \\
\text { Level Is: }\end{array}$ & $\begin{array}{l}\text { My Perception of Evans' } \\
\text { ServicePerformance Is: }\end{array}$ \\
\hline & Low High & Low High & $\begin{array}{l}\text { Low } \\
\quad \text { Oping No }\end{array}$ \\
\hline $\begin{array}{l}\text { Q.1 Prompt service } \\
\text { to customers }\end{array}$ & $\begin{array}{lllllllll}1 & 2 & 3 & 4 & 5 & 6 & 7 & 8 & 9\end{array}$ & $\begin{array}{lllllllll}1 & 2 & 3 & 4 & 5 & 6 & 7 & 8 & 9\end{array}$ & $\begin{array}{llllllllll}1 & 2 & 3 & 4 & 5 & 6 & 7 & 8 & 9 & \mathrm{~N}\end{array}$ \\
\hline
\end{tabular}

Q.4 Providing service at the promised time

Q.5 Employees who understand the needs of their customers

Q.6 Visually appealing materials associated with the service (e.g., clear and concise forms)

Q.7 Having the customer's best interest at heart

Q.8 Willingness to help customers

Q.9 Maintaining error-free customer and catalog records

Q.10 Keeping customers informed about when services will be performed

Q.11 Providing services as promised

Q.12 Employees who instill confidence in customers
Q.13 Employees who have the knowledge to answer customers' questions

Q.15 Dependability in handling customers' service problems

Q.14 Readiness to respond to customers' questions

Q.16 Performing services right the first time

Q.17 Visually appealing facilities

Q.18 Giving customers individual attention

Q.19 Employees who have a neat, professional appearance

Q.20 Convenient business hours

Q.21 Modern equipment

Q.22 Assuring customers of the accuracy and confidentiality of their transactions and the number and generic nature of the dimensions. White and Abels conclude that, with slight modifications, the survey can adequately reflect the range of values that library users attach to information centers.

\section{Methodology}

Background

Texas A\&M University (TAMU), located in College Station, has approximately
44,000 students of which nearly 20 percent are graduate students. The university employs approximately 2,500 faculty and 13,000 staff members. The Sterling C. Evans Library is the main library servicing the educational and research needs of the university and the local community. With more than two million volumes, four million microforms, and 13,000 periodical subscriptions, the library is the major informa- 
tion resource for TAMU students and faculty.

The library offers its customers many services, including orientations, tours and demonstrations, book and journal circulation privileges, interlibrary loan services, remote computer access to the library computer system, access to computerized literature searches, access to audiovisual materials and equipment, more than $150 \mathrm{mi}$ crocomputers, and other services. As their comments indicate, many of these services were considered during the customers' evaluation of the quality of the library's service.

\section{Research Questions}

Service quality is measured in terms of how well a provider performs with regard to a customer's expectations. ${ }^{9}$ Data gathered from the measurement of service quality can be used to answer the following researched questions:

1. How do customers define library service quality?

2. How can library service quality be improved?

3. What dimensions of quality are most important to library customers?

\section{The Survey Instrument}

This survey is based on the model SERVQUAL designed by Berry, Parasuraman, and Zeithaml, a multiple-item scale used to measure customer expectations and perceptions of service quality. ${ }^{10}$ The survey is divided into two parts. Part 1 (see figure 1 for a partial sample survey) contains three sets of twentytwo questions each, where a customer indicates his or her minimum, perceived, and desired service acceptance levels on a scale ranging from a low of 1 to a high of 9. The twenty-two questions can be divided into five sets, each of which represents one of the five dimensions of quality (reliability, responsiveness, assurance, empathy, and tangibles). Part 2 (see figure 2 for a partial sample survey) allows the customer to give an overall rating of library service quality and to weigh five different dimensions of quality pertaining to services offered in academic libraries. Berry, Parasur-aman, and Zeithaml speak in terms of a zone of tolerance, which is the area between the minimum and desired acceptance levels. Quality is measured by determining where perceived performance falls with respect to the zone of tolerance. Scores also can be weighted to measure quality with respect to the dimension(s) most important to the customer.

The original SERVQUAL survey questions were slightly modified to be more specific to the library. They were listed randomly so that sets of dimensional questions were not all grouped together. This was done to eliminate any biases a respondent may have had with respect to a particular dimension.

To ensure validity of the survey instrument, Berry, Parasuraman, and Zeithaml derived the five dimensions from a systematic analysis of customer ratings from hundreds of interviews in several service sectors. SERVQUAL also was tested in five different service sectors: product repair and maintenance, retail banking, long-distance telephone, securities brokerage, and credit cards. The dimensions were determined to be a concise depiction of the core criteria that customers apply in assessing service quality. ${ }^{11}$

To supplement the raw data from the survey, the authors posed the following question at the end of the survey: "If you could say anything to the Director of Evans Library, what would it be?" By soliciting input in this manner, the comments provided explanations for the survey raw data.

\section{Data Collection and Processing}

A total of 525 surveys was sent out: 125 each to faculty, staff, graduate, and undergraduate students; and 25 to com- 


\section{FIGURE 2}

\section{Evans Library Customer Satisfaction Survey, Part 2}

1. How would you rate the overall quality of service provided by Evans Library?

(Circle one number below.)

\section{Extremely Poor \\ 12}

\section{4}

$\begin{array}{lrr}\text { Extremely } & \text { Good } \\ 7 & 8 & 9\end{array}$

2. Listed below are five general features pertaining to academic libraries and the services they offer. We would like to know how important each of these features is to you when you evaluate an academic library's quality of service.

Please allocate a total of 100 points among the five features according to how important each feature is to you-the more important a feature is to you, the more points you should give it. Please be sure the points you give add up to 100 .

1. The appearance of the library's physical facilities, equipment, personnel, and communications materials.

2. The library's ability to perform the promised services dependably and accurately.

3. The library's willingness to help customers and provide prompt service.

4. The knowledge and courtesy of the library's employees and their ability to convey trust and confidence.

5. The caring, individualized attention the library provides its customers.

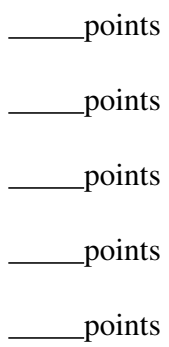

Total Points Allocated

100 points

munity users. Surveys sent to faculty and students were distributed in proportion to the size of the respective school (i.e., engineering, architecture, etc.). Names of survey recipients were randomly generated by computer databases. The above steps were taken to ensure reliability of the survey results. To encourage selected participants to respond, the authors offered them small tokens of appreciation and the option to receive the results of the survey if they so desired.

The responses from each survey were manually entered into a computerized file manager. A printout was made of the raw data so that the authors could more easily double-check entries for any errors. Once the data had been double-checked, they were imported into spreadsheet software for the purpose of plotting graphs. It should be noted that some of the survey participants had never visited the library before. On the survey, they were asked to enter "No opinion" for all responses where they had no perception of service performance. Any averages calculated from the data were based on the number of responses to a question. There was no numerical value attached to the "No opinion" response.

Results are analyzed by determining where the perceived data points fall with respect to the zone of tolerance. Any data points falling within the zone indicate that the customer finds the service tolerable, those falling below the zone indicate that the customer's mini$\mathrm{m}$ u $\mathrm{m}$ acceptable service requirements have not been met; and those falling above 
the zone indicate that the customer's desired service level has been exceeded. ${ }^{12}$ Each of the twenty-two questions is treated as a separate entity and has its own zone of tolerance. There is no set range for the zone of tolerance because it is

\begin{tabular}{|lcccc|}
\hline \multicolumn{5}{c|}{ TABLE 2 } \\
Averages by Category & \\
\hline \hline & $\begin{array}{c}\text { Surveys } \\
\text { Received }\end{array}$ & $\begin{array}{c}\text { Average } \\
\text { Minimum }\end{array}$ & $\begin{array}{c}\text { Average } \\
\text { Perceived }\end{array}$ & $\begin{array}{c}\text { Average } \\
\text { Desired }\end{array}$ \\
\hline Faculty & 35 & 6.3 & 6.3 & 8.0 \\
Staff & 23 & 6.4 & 6.0 & 7.9 \\
Graduate & 64 & 6.3 & 6.2 & 8.0 \\
Undergrad. & 70 & 6.2 & 6.2 & 8.0 \\
Community & 6 & 5.5 & 7.3 & 8.2 \\
\hline Total/Avg. & 198 & 6.1 & 6.4 & 8.0 \\
\hline
\end{tabular}
based sole-ly on the customer's minimum acceptable service level and desired level of performance. However, the goal is that the perceived scores will either equal or surpass the minimum level of performance.

To better illustrate the zone of tolerance concept, the authors used bar graphs. (Graphs are explained in greater detail in the section on survey results.) Question numbers are represented on the X-axis, and levels of performance (minimum, perceived, and desired) for each series are graphed on the Y-axis.

\section{Calculations}

(Note: Instructions for calculations are attributed to Zeithaml, Parasuraman, and Berry. ${ }^{13}$ )

Unweighted SERVQUAL Scores. Unweighted scores are those scores calculated without taking into account the relative importance that customers attached to a dimension. They are calculated by averaging customers' SERVQUAL scores on the statements comprising a dimension. For example, if $N$ customers responded to a SERVQUAL survey, the average SERVQUAL score along each dimension is obtained by following these steps:

1. For each customer, add the SERVQUAL scores on the statements pertaining to the dimension and divide the sum by the number of statements making up the dimension.
2. Add the quantity obtained in step one across all $N$ customers and divide the total by $N$. To obtain an overall average of service quality, average the SERVQUAL scores over the five dimensions (i.e., summed and divided by five).

Weighted SERVQUAL Scores. Weighted scores take into account the relative importance of the dimensions. The following steps were taken to calculate the weighted scores:

1. For each customer, add the SERVQUAL scores on the statements pertaining to the dimension and divide the sum by the number of statements making up the dimension.

2. For each customer, multiply the SERVQUAL score for each dimension (obtained in step one) by the importance weight assigned by the customer to that dimension. The importance weight is the points the customer allocated to the dimension divided by 100 .

3. For each customer, add the weighted SERVQUAL scores (obtained in step two) across all five $\mathrm{d} i$ mensions to obtain a combined SERVQUAL score.

4. Add the scores (obtained in step three) across all $N$ customers and divide the total by $N$.

\section{Survey Results}

Nearly 200 completed surveys were returned. The overall response rate was 38 percent. The highest response came from the students, where more than 50 


\begin{tabular}{|lcllc|}
\hline \multicolumn{5}{c|}{ TABLE 3 } \\
\multicolumn{5}{|c|}{$\begin{array}{c}\text { Frequency of Visitation } \\
\text { to the Evans Library }\end{array}$} \\
\hline \hline$n=198$ & Daily & Weekly & Monthly & Never \\
\hline Faculty & $12.5 \%$ & $46.9 \%$ & $37.5 \%$ & $3.1 \%$ \\
Staff & 4.5 & 18.2 & 63.6 & 13.6 \\
Graduate & 24.2 & 50.0 & 24.2 & 1.6 \\
Undergrad. & 24.3 & 52.9 & 21.4 & 1.4 \\
Community & 0.0 & 16.7 & 66.7 & 16.7 \\
\hline
\end{tabular}

rect comments from the customer to the library director, very specific feedback was provided. Most survey participants expressed areas of dissatisfaction with the library. Topics commented on included: difficulty in finding resources, circulation policies, unpleasant library staff, expenses associated with duplication services, outdated resources, building accessibility

percent responded. The survey scale ranges from a low of 1 to a high of 9 . By taking the average of the twenty-two questions (which encompass all five dimensions), the average levels of acceptance are shown in table 2.

Of those responding to the survey, more than 83 percent had visited the library before. Nearly 50 percent of the faculty and student respondents visit the library weekly. More than 60 percent of the responding staff and community users visit the library on a monthly basis. Table 3 shows the frequency of visitation based on the groups surveyed.

In Part 2 of the survey, participants ranked dimensions by allocating 100 points among them to indicate each dimension's importance. Reliability ranked first, with responsiveness a close second. Empathy was determined to be the least important dimension. In comparison to "other studies" conducted by Berry and colleagues, the dimensions were ranked in the same order with the exception of tangibles and empathy. The relative importance of dimensions for both studies was similar for responsiveness, assurance, and empathy, as shown in table $4 .{ }^{14}$

In the portion of the survey allotted for di- hours, and missing/lost materials. The more positive comments pertained to the attitude and work ethics of the library staff.

The unweighted SERVQUAL scores across each individual dimension (tangibles, reliability, responsiveness, assurance, and empathy) are shown on the graphs in figures 3-7. On the graphs, a blank gap indicates room for possible improvement, shaded areas show acceptable service, and solid black areas indicate unacceptable service. Figure 1, Tangibles, is the only dimension where the library consistently performed within the zone of tolerance (i.e., perceived scores are between desired and minimum). Figure 8 shows the scores averaged over the five dimensions; reliability shows the highest minimum and desired service scores indicating that customers expect the most, and will tolerate the least, in this dimension.

\section{TABLE 4}

\section{Relative Importance of Service Quality Dimensions}

\begin{tabular}{lccc} 
& & \multicolumn{2}{c}{ Relative Importance } \\
Dimension & Rank & $\begin{array}{c}\text { This Study } \\
\mathrm{n}=198\end{array}$ & $\begin{array}{c}\text { Other Studies } \\
\mathrm{n}=1,936\end{array}$ \\
\hline Reliability & 1 & $26.7 \%$ & $32 \%$ \\
Responsiveness & 2 & 23.6 & 22 \\
Assurance & 3 & 18.8 & 19 \\
Tangibles & 4 & 16.2 & $11^{*}$ \\
Empathy & 5 & 14.8 & $16^{*}$ \\
\hline
\end{tabular}

* Note differences in rankings of "This Study" vs "Other Studies." 

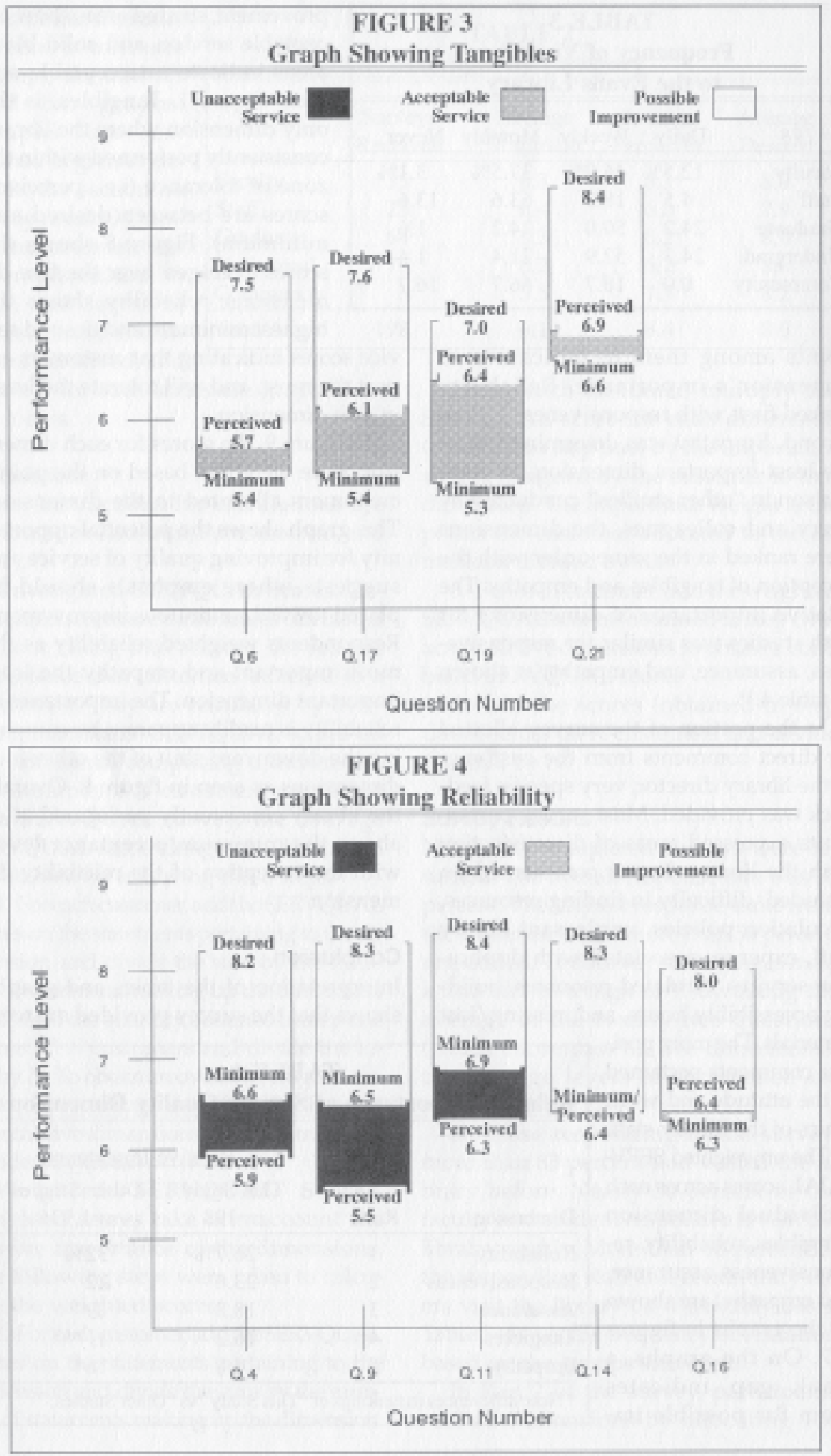
Toward a TQM Paradigm 245
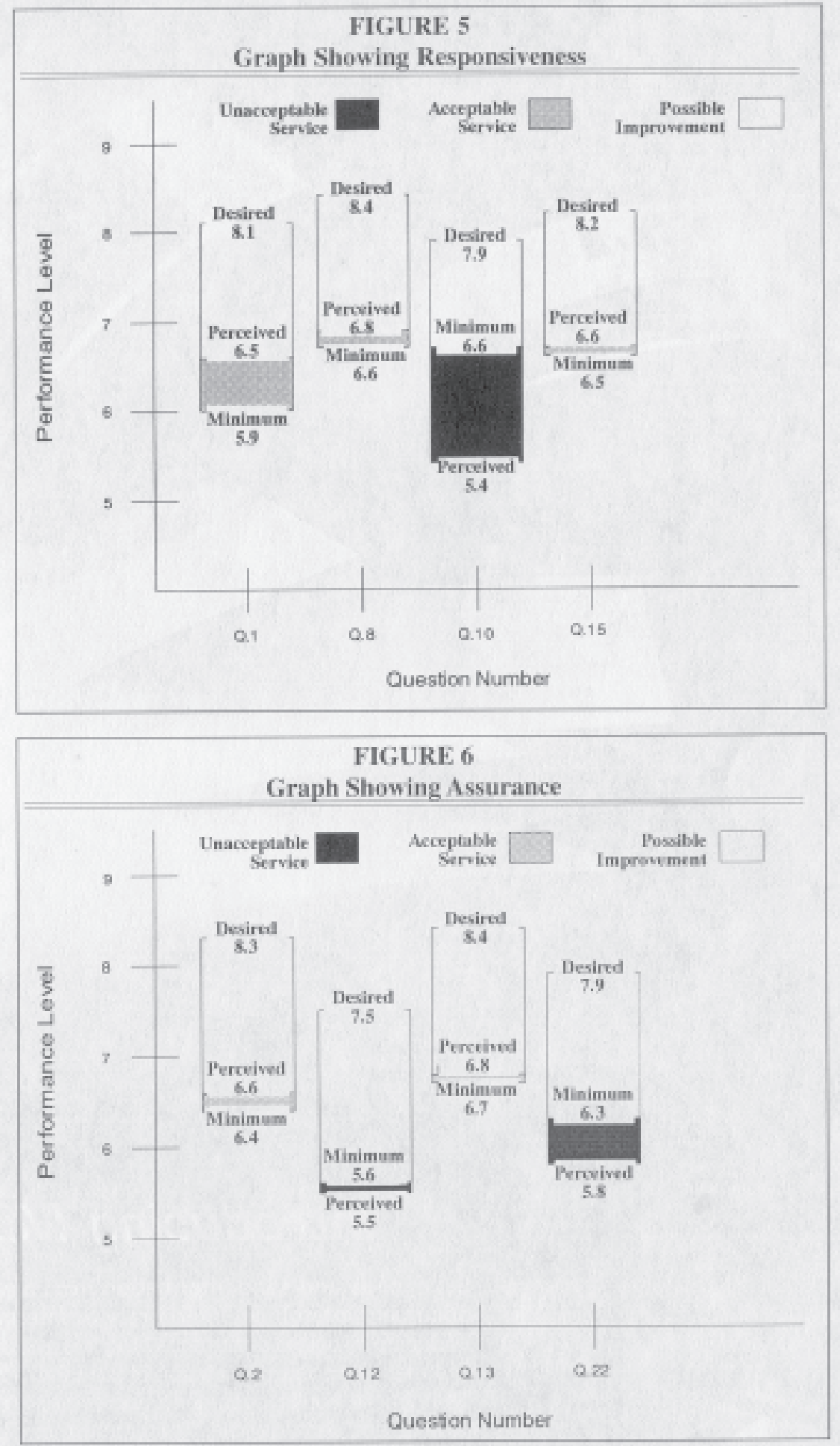

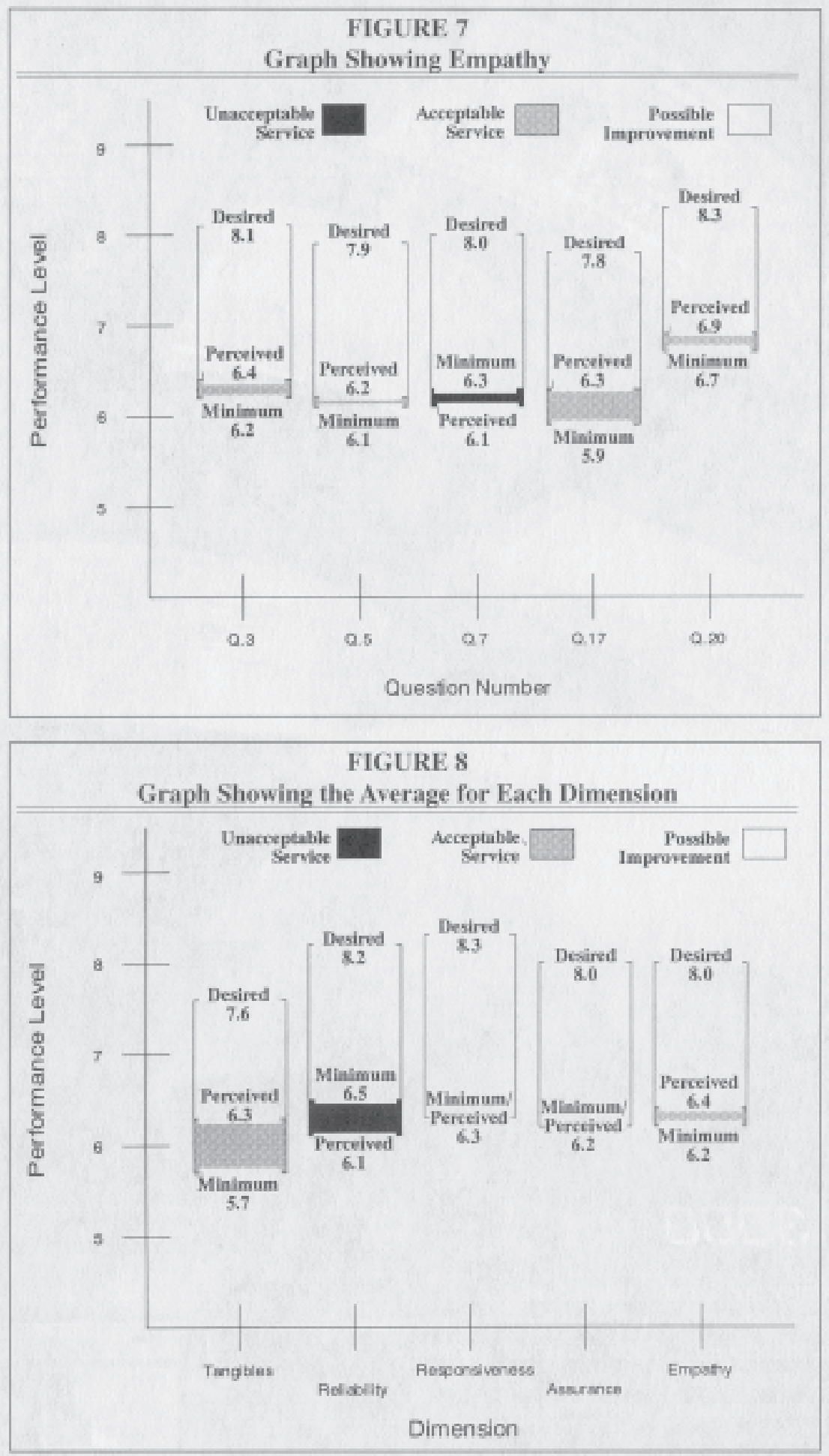


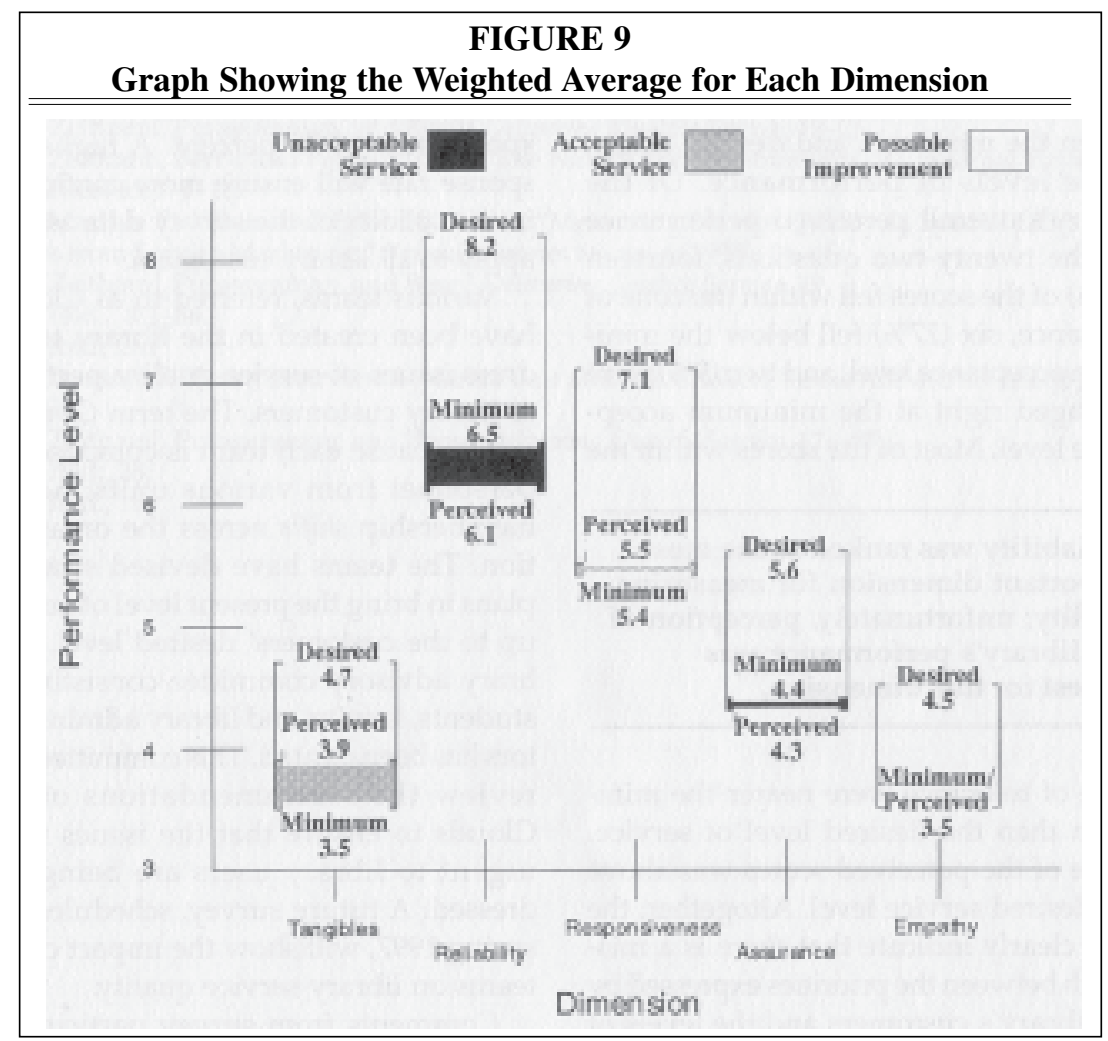

In figure 9, the scores for each dimension were weighted based on the points customers allocated to the dimension. This graph shows the potential opportunity for improving quality of service and suggests where emphasis should be placed toward continuous improvement. Respondents weighted reliability as the most important and empathy the least important dimension. The importance of reliability is readily apparent by comparing the downward shift of the other four dimensions as seen in figure 9. Overall, the library consistently performed at or above the minimum acceptance level, with the exception of the reliability dimension.

\section{Conclusion}

Interpretation of the tables and graphs shows that the survey provided answers to the original research questions.
Those questions were:

1. How do customers define library service quality?

2. How can library service quality be improved?

3. What dimensions of quality are most important to library customers?

Customers define service quality as the extent of discrepancy between their expectations or desires and their perceptions. ${ }^{15}$ In this study, discrepancies prevailed along dimensions of reliability, responsiveness, assurance, and empathy. Only the tangibles dimension (appearance of physical facilities, equipment, personnel, and communication materials) surpassed the customers' minimum acceptable service level, and this dimension was viewed by customers as the second least important for measuring quality. Tangibles was 
the only dimension where the library performed consistently within the zone of tolerance.

For this study, customer ranking of the relative importance of the five service quality dimensions is as follows: reliability, responsiveness, assurance, tangibles, and empathy. These findings are not unique in that other studies have consistently shown similar results, with the exception of tangibles and empathy. Reliability relates to the library's

\section{Reliability was ranked as the most important dimension for measuring quality; unfortunately, perception of the library's performance was lowest for this dimension.}

ability to perform promised services dependably and accurately. It was ranked as the most important dimension for measuring quality; unfortunately, perception of the library's performance was lowest for this dimension. Empathy (the caring, individualized attention the library provides its customers) was the least important of the five dimensions. The library definitely needs to improve in the areas of reliability and responsiveness because of their importance to customers.

The zone of tolerance is the area between the minimum and desired acceptance levels of performance. Of the library's overall perceived performance for the twenty-two questions, fourteen $(64 \%)$ of the scores fell within the zone of tolerance, six (27\%) fell below the minimum acceptance level, and two (9\%) were averaged right at the minimum acceptance level. Most of the scores within the zone of tolerance were nearer the minimum than the desired level of service. None of the perceived scores was above the desired service level. Altogether, the data clearly indicate that there is a mismatch between the priorities expressed by the library's custom- ers and the levels of service quality delivered by the library.

\section{Topics for Further Investigation}

Several variables may have impacted the outcome of this investigation. For example, an individual's frequency of visitation to the library may have influenced survey scores. Also, services provided to customers vary by customer status (i.e., faculty, undergraduate, etc.). Those only receiving baseline services may have evaluated the library more harshly in some areas. The survey instrument was rather lengthy, and perhaps some individuals did not take the time to thoroughly read through it. For future surveys, more effort should be placed on increasing the response rate of 38 percent. A higher response rate will ensure more confidence in the validity of the survey data as they apply to all library customers.

Various teams, referred to as Clouds, have been created in the library to address issues of service quality pertinent to library customers. The term Clouds is used because each team is composed of personnel from various units; hence, membership shifts across the organization. The teams have devised strategic plans to bring the present level of service up to the customers' desired level. A library advisory committee consisting of students, faculty, and library administrators has been created. This committee will review the recommendations of the Clouds to ensure that the issues most urgent to library users are being addressed. A future survey, scheduled for spring 1997, will show the impact of the teams on library service quality.

Comments from survey participants indicated that library users do not look at the operation of individual units within the library system but, instead, view the library as one enterprise. For example, survey participants expressed dissatisfaction with book availability within the 
library but did not specifically attack the Circulation Department, which is responsible for shelving, or Collection Development, which reorders missing materials. The challenge for the Evans Library is to provide great service as a system by continually improving upon the services provided by each unit.

\section{Notes}

1. Rosanna M. O'Neil, Total Quality Management in Libraries: A Sourcebook (Englewood, Colo.: Libraries Unlimited, 1994), 2.

2. Valarie A. Zeithaml, A. Purasuraman, and Leonard L. Berry, Delivering Quality Service: Balancing Customer Perceptions and Expectations (New York: Free Pr., 1990), 19-26.

3. O'Neil, Total Quality Management in Libraries, 6-7.

4. Françoise Hebert, "Service Quality: An Unobtrusive Investigation of Interlibrary Loan in Large Public Libraries in Canada," LISR 16 (1994): 3-21.

5. Valarie A. Zeithaml, Leonard L. Berry, and A. Parasuraman, "The Nature and Determinants of Customer Expectations of Service," Journal of the Academy of Marketing Science 21, no. 1 (1993): 1-12.

6. Zeithaml, Purasuraman, and Berry, Delivering Quality Service, 19-26.

7. Zeithaml, Berry, and Parasuraman, "The Nature and Determinants of Customer Expectations of Service," 1-12.

8. Marilyn D. White and Eileen G. Abels, "Measuring Service Quality in Special Libraries: Lessons from Service Marketing," Special Libraries 86, no. 4 (1995): 36-45.

9. Zeithaml, Purasuraman, and Berry, Delivering Quality Service, 19.

10. Ibid., 181-86.

11. Ibid., 26.

12. Leonard L. Berry, interview by Linda Bair and Bill Chollett, Texas A\&M University, June 1994.

13. Zeithaml, Purasuraman, and Berry, Delivering Quality Service, 176-77.

14. Ibid., 28.

15. Ibid., 19. 